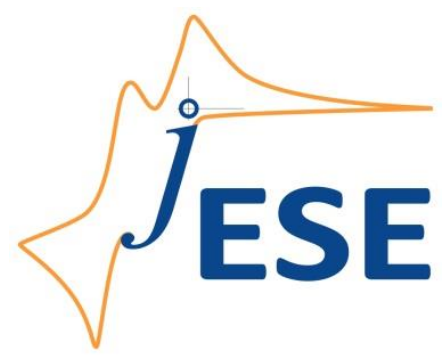

Open Access : : ISSN 1847-9286

www.jESE-online.org

Editorial

\title{
Advanced electrochemical sensors based on the functional carbon materials
}

Hadi Beitollahi

Environment Department, Institute of Science and High Technology and Environmental Sciences, Graduate University of Advanced Technology, Kerman, Iran; ; email: h.beitollahi@yahoo.com

There is a growing need for fast, robust, and reliable methods for the selective determination of organic compounds in various matrices of importance for human health and well-being. Searching through the recent scientific literature revealed the ever-increasing trend of a number of papers published annually on different topics related to electrochemical sensors [1]. As the electrochemical techniques are well established and easy to use, the scientific interest is focused on emerging applications such as non-invasive point-of-care (POC) devices and disposable wearable sensors.

There are many different concepts on how to approach the sensor design, which often includes tailoring the surfaces by functional molecules of various physico-chemical properties, size, and compositions. The versatility of approaches for the sensor design offers practically unlimited possibilities for the researchers and analytical chemists to direct the development of the sensors toward more accurate and non-disposable devices useful in essential fields of interest such as human health and environmental protection.

The present special issue of the Journal of Electrochemical Science and Engineering aimed to give a short overview of the various state-of-the-art technologies for the implementation of different forms of carbon nanomaterials such as carbon nanotubes, graphene derivatives, carbon nano-dots, active carbon, screen-printed carbon electrode and others to design novel electrochemical sensors. The special issue attracted great interest and there are 18 papers selected for publishing.

In the review by Manjunatha et al. [2], the new developments of carbon-based materials for the determination of hormones are presented. In another review, the possibility of using an electrochemical biosensor in the diagnosis of Covid-19 and thus in contributing to the fast and accurate diagnostic practices during Covid pandemic was thoroughly analysed [3]. The Covid-19 analysis was also addressed in the paper by Sari et al. [4].

Most of the papers applied modifications of screen-printed carbon electrodes to prepare selective sensors for various organic compounds. Graphene, graphene oxide or carbon nanotubes and their derivatives were mainly used, such as nitrogen-doped graphene [5], $\mathrm{Cu}_{2} \mathrm{O} / \mathrm{Fe}_{2} \mathrm{O}_{3}$ modified reduced graphene oxide [6], graphene oxide modified with $\mathrm{Fe}_{2} \mathrm{O}_{3}$ nanoparticles [7], multi-wall carbon nanotubes [8]. Graphene quantum dots were used to modify carbon paste electrode for the selective determination of levodopa [9]. Screen-printed carbon electrode were also modified with 
Nafion/ $/ \mathrm{TiO}_{2}$ for the selective determination of olopatadine [10] and with $\mathrm{Cu}$ complexes for the simultaneous determination of dopamine and uric acid [11]. Modified carbon paste electrodes were also used in the determination of nickel contamination [12] and glutathione [13].

Analysis of ciprofloxacin in blood was achieved with the construction of the selective sensor based on the iron-doped graphitic carbon nitride [14].

In the paper by Pereira et al. [15], the development of multiwalled carbon nanotube ink was described for its application in electrochemical sensors, and in the paper by Araujo et al. [16], graphene papers were functionalized to increase the efficiency of enzyme immobilization.

\section{References}

[1] J. Bobacka, Journal of Solid State Electrochemistry 24 (2020) 2039-2040. https://doi.org/ 10.1007/s10008-020-04700-4

[2] J. G. Manjunatha, G. Tigari, H. Nagarajappa, N. S. Prinith, Journal of Electrochemical Science and Engineering 12(1) (2022) 3-23. https://doi.org/10.5599/jese.1094

[3] R. K. Satvekar, Journal of Electrochemical Science and Engineering 12(1) (2022) 25-35. https://doi.org/10.5599/jese.1116

[4] A. K. Sari, Y. W. Hartati, S. Gaffar, I. Anshori, D. Hidayat, H. L. Wiraswati, Journal of Electrochemical Science and Engineering 12(1) (2022) 217-. https://doi.org/10.5599/jese.1206

[5] S. Esfandiari Baghbamidi, Journal of Electrochemical Science and Engineering 12(1) (2022) 37-45. https://doi.org/10.5599/jese.1103

[6] F. Irannezhad, J. Seyed-Yazdi, S. H. Hekmatara, Journal of Electrochemical Science and Engineering 12(1) (2022) 45-55. https://doi.org/10.5599/jese.1101

[7] H. Tashakkorian, B. Aflatoonian, P. Mohammadzadeh Jahani, M. R. Aflatoonian, Journal of Electrochemical Science and Engineering 12(1) (2022) 69-77. https://doi.org/10.5599/ jese.1145

[8] S. A. Ahmadi, S. Z. Mohammadi, M. Jafari, P. Mohammadzadeh Jahani, R. Mashayekh, Journal of Electrochemical Science and Engineering 12(1) (2022) 125-133. https://doi.org/ 10.5599/jese.1141

[9] P. Mohammadzadeh Jahani, Journal of Electrochemical Science and Engineering 12(1) (2022) 79-88. https://doi.org/10.5599/jese.1133.

[10] M. Mehmandoust, A. Mehmandoust, N. Erk, Journal of Electrochemical Science and Engineering 12(1) (2022) 89-101. https://doi.org/10.5599/jese.1117

[11] H. Beitollahi, S. Tajik, M. R. Aflatoonian, A. Makarem, Journal of Electrochemical Science and Engineering 12(1) (2022) 197-206. https://doi.org/10.5599/jese.1231

[12] K. Pokpas, N. Jahed, P. Bezuidenhout, S. Smith, K. Land, E. Iwuoha, Journal of Electrochemical Science and Engineering 12(1) (2022) 151-162. https://doi.org/10.5599/jese.1173

[13] H. Beitollahi, S. Tajik, M. R. Aflatooniand, A. Makarem, Journal of Electrochemical Science and Engineering 12(1) (2022) 207-215. https://doi.org/10.5599/jese.1230

[14] H. S. Vedhavathi, B. P. Sanjay, M. Basavaraju, B. S. Madhukar, N. K. Swamy, Journal of Electrochemical Science and Engineering 12(1) (2022) 57-68. https://doi.org/10.5599/jese.1112

[15] A. E. F. Oliveira, A. C. Pereira, L. F. Ferreira, Journal of Electrochemical Science and Engineering 12(1) (2022) 103-124. https://doi.org/10.5599/jese.1134

[16] J. Luzardo, D. Aguiar, A. Silva, S. Oliveira, B. Archanjo, R. Simão, J. Araujo, Journal of Electrochemical Science and Engineering 12(1) (2022) 135-149. https://doi.org/10.5599/ jese.1099

(C)2022 by the authors; licensee IAPC, Zagreb, Croatia. This article is an open-access article distributed under the terms and conditions of the Creative Commons Attribution license (https://creativecommons.org/licenses/by/4.0/) 